\title{
Persepsi Masyarakat terhadap Usaha Anyaman Enceng Gondok Di Desa Banyu Hirang Kecamatan Amuntai Selatan Kabupaten Hulu Sungai Utara
}

\section{(Community Perception of Business Water Hyacinth Woven in Banyu Hirang Village Amuntai Selatan District Hulu Sungai Utara Regency)}

\author{
Miranda Romaully Br. Sitanggang ${ }^{1)}$ \& Juwairiah ${ }^{2)}$ \\ Program Studi Agribisnis, Sekolah Tinggi Ilmu Pertanian Amuntai \\ ${ }^{1)}$ miranda.rsd2203@gmail.com \\ 2)jwrh@gmail.com
}

\begin{abstract}
ABSTRAK
Penelitian ini bertujuan untuk mengetahui persepsi masyarakat terhadap dampak positif dan dampak negatif usaha anyaman enceng gondok di Desa Banyu Hirang Kecamatan Amuntai Selatan Kabupaten Hulu Sungai Utara. Penelitian ini menggunakan pengumpulan data menggunakan kuesioner (angket). Persepsi masyarakat jelas terlihat bahwa pada dampak positif nilai skor rata masyarakat umumnya adalah 59,8 dan dari masyarakat pengrajin sebesar 63,3 pada keseluruhan untuk keduanya mendapatkan rata-rata 61,55 pada garis kontinum berada pada daerah sangat setuju, yang mana berarti bahwa persepsi masyarakat terhadap dampak positif pada usaha anyaman enceng gondok dilihat dari segi aspek ekonomi, sosial, budaya dan lingkungan adalah sangat memberikan dampak positif terhadap masyarakat. Sedangkan pada dampak negatif nilai skor rata masyarakat umumnya adalah 53,3 dan dari masyarakat pengrajin sebesar 49,2 pada keseluruhan untuk keduanya mendapatkan rata-rata 51,25 pada garis kontinum berada pada daerah setuju yang mana berarti bahwa persepsi masyarakat terhadap dampak negatif pada usaha anyaman enceng gondok dilihat dari segi aspek ekonomi, sosial, budaya dan lingkungan adalah memberikan dampak negatif terhadap masyarakat.
\end{abstract}

Kata Kunci : Persepsi, masyarakat, anyaman, enceng gondok.

\begin{abstract}
This study aims to determine the public perception of the positive and negative effects of water hyacinth woven business in Banyu Hirang Village, South Amuntai District, Hulu Sungai Utara District. This study uses data collection using a questionnaire (questionnaire). The public perception clearly shows that the positive impact of the average community score is 59.8 and from the craftsmen community 63.3 in total for both get an average of 61.55 on the continuum line in the area strongly agree, which means that perception The community has a positive impact on the economic, social, cultural and environmental aspects of the water hyacinth webbing business, which has a very positive impact on the community. Whereas the negative impact of the average score of the general community is 53.3 and that of the craftsmen community is 49.2 in total for both the average 51.25 on the continuum line in the agreed area which means that the community's perception of the negative impact on the business water hyacinth webbing seen in terms of economic, social, cultural and environmental aspects is a negative impact on society.
\end{abstract}

Keywords: Perception, society, webbing, water hyacinth.

\section{PENDAHULUAN}

Agribisnis memiliki beberapa subsistem, salah satunya adalah subsitem pengolahan (down stream agribusiness) yakni industri yang mengolah komoditas pertanian primer (agroindustri) menjadi produk olahan baik produk antara (intermediate product) maupun produk akhir (pinish product). Termasuk didalamnya industri makanan, industri minuman, industri barang-barang serat alam (barang-barang karet) paliwood, pulp, kertas, bahan-bahan bangunan terbuat dari kayu, rayon, benang dari kapas/sutera, barangbarang kulit, tali dan karung goni) industri biofarmaka dan industri agrowisata serta estetika (Sutawi, 2002).

Salah satu industri yang dimiliki oleh Kabupaten Hulu Sungai Utara adalah Industri anyaman eceng gondok merupakan salah satu dari usaha di bidang agribisnis sekaligus 
merupakan produk kebanggan masyarakat di Kecamatan Amuntai Selatan khususnya di Desa Banyu Hirang. Enceng gondok merupakan tumbuhan vaskuler yang terapung bebas di atas permukaan air bila perairan cukup dalam. Enceng gondok memiliki kemampuan menyesuaikan diri yang sangat baik dengan berbagai keadaan lingkungan sehingga dapat tumbuh baik dengan keadaan subur dan kurang subur. Dalam satu musim, dari satu enceng gondok dapat berbentuk 5000-6000 tunas baru sehingga perkembangbiakannya luar biasa tinggi. Oleh sebab itu, enceng gondok selalu sulit di berantas karena memiliki pekembangbiakan spektakuler (Kaleka dan Hartono, 2013).

Anyaman enceng gondok ini bisa dikatakan cukup baru dikembangkan dari pada kerajinan anyaman lain seperti anyaman purun, bambu, rotan plastik dan lain-lain di Kabupaten Hulu Sungai Utara. Data yang di peroleh dari Dinas Perindustrian dan Perdangangan Kabupaten Hulu Sungai Utara terdapat 11 jenis komoditi produk industri yang ada di Hulu Sungai Utara.

Tabel 1. Data Industri Unggulan Kabupaten Hulu Sungai Utara Tahun 2016.

\begin{tabular}{clccccc}
\hline No & \multicolumn{1}{c}{ Komoditi } & $\begin{array}{c}\text { Unit usaha } \\
(\mathrm{bh})\end{array}$ & $\begin{array}{c}\text { Tenaga kerja } \\
(\text { org })\end{array}$ & $\begin{array}{c}\text { Investasi } \\
(\mathrm{Rp})\end{array}$ & $\begin{array}{c}\text { Produksi } \\
(\mathrm{Rp})\end{array}$ & $\begin{array}{c}\text { Bahan baku } \\
(\mathrm{Rp})\end{array}$ \\
\hline 1 & Anyaman purun & 13.334 & 23.275 & 12.199 .725 & 8.825 .015 & 8.002 .529 \\
2 & Anyaman bambu & 381 & 566 & 427.219 & 1.613 .560 & 1.165 .968 \\
3 & Anyaman rotan /lupu & 355 & 550 & 428.893 & 1.785 .050 & 1.011 .320 \\
4 & Anyaman enceng gondok & 269 & 425 & 125.175 & 115.250 & 85.790 \\
5 & Anyaman plastik & 341 & 549 & 153.525 & 255.185 & 101.894 \\
6 & Anyaman bamban & 137 & 241 & 106.425 & 92.863 & 72.502 \\
7 & Atap/lampit rumbia & 221 & 344 & 212.290 & 91.742 & 78.273 \\
8 & Lampit rotan & 167 & 305 & 1.625 .550 & 6.932 .028 & 3.054 .138 \\
9 & Kerajinan ukiran & 205 & 275 & 245.750 & 522.011 & 402.443 \\
10 & Pembuatan jala & 341 & 802 & 642.325 & 702.751 & 500.870 \\
11 & Kembang dalam botol & 1 & 3 & 3.750 & 48.250 & 34.025 \\
\hline \multicolumn{2}{l}{ Jumlah } & 15.752 & 27.535 & 16.170 .627 & 18.002 .705 & 14.509 .752 \\
\hline
\end{tabular}

Sumber: Dinas Perindustrian dan Perdagangan Kabupaten Hulu Sungai Utara (2017).

Perkembangan usaha ini pun sangat baik dan tentunya mampu bertahan sebagai salah satu produk daerah unggulan di Kabupaten Hulu Sungai Utara oleh karena itu minat masyarakat untuk mendirikan usaha ini meningkat, sampai pada saat ini sudah mencapai 269 unit usaha anyaman enceng gondok yang berdiri di Kabupaten Hulu Sungai Utara dan sudah mempunyai pengrajin/tenaga kerja 425 orang salah satu usahanya ada di Desa Banyu Hirang. Setiap usaha yang dijalankan tentu mempunyai pengaruh/dampak positif dan negatif, baik itu dari segi aspek ekonomi, aspek sosial, aspek budaya dan aspek lingkungan.

Penelitian bertujuan untuk mengetahui (i) persepsi masyarakat terhadap dampak positif usaha anyaman enceng gondok dari aspek ekonomi, sosial, budaya dan lingkungan yang berada di Desa Banyu Hirang (ii) persepsi masyarakat terhadap dampak negatif usaha anyaman enceng gondok dari aspek ekonomi, sosial, budaya dan lingkungan yang berada di Desa Banyu Hirang.

\section{METODOLOGI PENELITIAN}

\section{Waktu dan Tempat}

Penelitian ini dilaksanakan di Desa Banyu Hirang Kecamatan Amuntai Selatan Kabupaten Hulu sungai Utara. Penelitian dilakukan mulai bulan Januari sampai dengan Juni 2017 dengan kegiatan meliputi persiapan, pengumpulan, pengolahan dan analisis data serta pembuatan laporan penelitian.

\section{Jenis dan Sumber Data}

Jenis data yang digunakan pada penelitian ini adalah data kualitatif. Data kualitatif adalah data yang di perjelas dari pendapat dan tanggapan masyarakat kemudian diolah dalam bentuk prosentase 
dan menjadi data kuantitatif. Data kuantitatif adalah penilaian yang dilakukan berdasarkan jumlah sesuatu/format terstruktur seperti matematika dan statistik.

Sumber data yang dikumpulkan dalam penelitian ini terdiri dari data primer, data sekunder dan studi pustaka. Data primer didapat dari hasil wawancara langsung, sedangkan data sekunder dan studi pustaka di peroleh dengan cara mengumpulkan dari Dinas, Instansi dan buku-buku yang terkait dengan penelitian ini.

\section{Metode Penarikan Sampel}

Penarikan sampel dengan menggunakan penarikan sampel Proportionate Stratified Random Sampling yaitu pengambilan sampel dari anggota populasi secara acak dan berstrata secara proporsional, dilakukan sampling ini apabila anggotanya heterogen (tidak sejenis).

- Jumlah kepala keluarga $=146 \mathrm{KK}$

- Jumlah pengrajin = 15 orang

Penentuan jumlah sampel untuk masyarakat umum dapat ditentukan sebagai berikut :

$$
\begin{gathered}
\frac{\text { jumlah pengrajin }}{\text { jumlah kepala keluarga }- \text { jumlah pengrajin }} \times 100 \% \\
\frac{15}{146-15} \times 100 \%=\frac{15}{131} \times 100 \% \frac{15}{131} \times 100 \%=0,11450 \times 131=14,9995
\end{gathered}
$$

\section{Analisis Data}

Analisis yang digunakan dalam penelitian ini yaitu digunakan analisis Deskriptif dimana aspek yang dilihat pada usaha anyaman enceng gondok seperti aspek ekonomi, sosial, budaya dan lingkungan terhadap dampak positif dan dampak negatif yang timbul oleh usaha anyaman enceng gondok tersebut. Analisis destriptif bertujuan untuk mengubah kumpulan data mentah menjadi mudah untuk dipahami dalam bentuk informasi yang lebih ringkas. Analisis deskriptif digunakan untuk mengidentifikasi persepsi masyarakat terhadap usaha anyaman enceng gondok melalui pengisian koesoner. Selanjutnya mengunakan analisis dengan teknik penskalaan likert, indikator-indikator yang dapat diukur melalui pertanyaan atau pernyataan, Selanjutnya dikatagorikan kedalam skor sebagai berikut :
Sangat Setuju (SS) $\quad: 5$

Setuju (S) : 4

Ragu-ragu (RG) : 3

Tidak Setuju (TS) : 2

Sangat Tidak Setuju (STS) : 1

Jawaban setiap item instrumen yang menggunakan skala likert mempunyai gradasi dari sangat positif sampai sangat negatif. Instrumen penelitian yang menggunakan skala likert dapat dibuat dalam bentuk checklist atau pilihan ganda. Kemudian dengan teknik pengumpulan data angket maka instrumen tersebut diberikan kepada semua sampel yang telah ditentukan untuk menjawabnya.

- Ketentuan skor tertinggi kali jumlah responden $=5 \times 15=75(\mathrm{SS})$

- Jumlah skor rendah kali jumlah responden $=1 \times 15=15$ (STS)

Secara kontinum dapat digambarkan sebagai berikut :

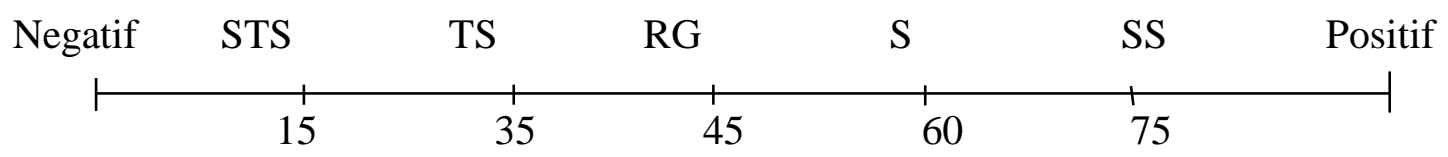

\section{Uji Hipotesis}

Uji hipotesis (Ha) merupakan anggapan dasar peneliti terhadap masalah yang sedang di kaji. Dalam hipotesis ini peneliti menganggap benar hipotesisnya yang kemudian akan dibuktikan secara emperis melalui pengujian hipotesis dengan menggunakan data yang diperoleh selama melakukan penelitian.

\section{HASIL DAN PEMBAHASAN}

\section{Hasil}

\section{Persepsi Masyarakat Umum}


Persepsi masyarakat adalah tanggapan atau pengetahuan lingkungan dari kumpulan individu-individu yang saling bergaul berinteraksi, karena mempunyai nilai-nilai, norma-norma, cara-cara dan prosedur merupakan kebutuhan bersama berupa suatu sistem adat istiadat yang bersifat kontinu (berkelanjutan/terus menerus) dan terikat oleh suatu identitas bersama yang di peroleh melalui interpretasi data indera. Berdasarkan hasil kuesioner yang di isi oleh masyarakat umum kemudian dianalisis berdasarkan skoring setiap jawaban responden. Berdasarkan skoring yang telah ditetapkan maka didapatkan hasil seperti tabel di bawah ini:

Tabel 1. Jumlah skor jawaban dari pernyataan untuk untuk responden masyarakat umum Tahun 2017.

\begin{tabular}{|c|c|c|c|}
\hline Sub Indikator & Indikator & No Pernyataan & Jumlah total Frekuensi (orang) x skor \\
\hline \multirow{7}{*}{$\begin{array}{c}\text { Aspek } \\
\text { Ekonomi }\end{array}$} & \multirow{3}{*}{ Manfaat } & 1 & 63 \\
\hline & & 2 & 60 \\
\hline & & 3 & 59 \\
\hline & \multirow{4}{*}{ Dampak } & 1 & 50 \\
\hline & & 2 & 40 \\
\hline & & 3 & 58 \\
\hline & & 4 & 67 \\
\hline \multirow{5}{*}{ Aspek Sosila } & \multirow{3}{*}{ Manfaat } & 1 & 63 \\
\hline & & 2 & 62 \\
\hline & & 3 & 61 \\
\hline & \multirow{2}{*}{ Dampak } & 1 & 54 \\
\hline & & 2 & 53 \\
\hline \multirow{4}{*}{ Aspek Budaya } & \multirow{2}{*}{ Manfaat } & 1 & 43 \\
\hline & & 2 & 61 \\
\hline & \multirow[t]{2}{*}{ Dampak } & 1 & 46 \\
\hline & & 2 & 42 \\
\hline \multirow{4}{*}{$\begin{array}{c}\text { Aspek } \\
\text { Lingkungan }\end{array}$} & \multirow{2}{*}{ Manfaat } & 1 & 61 \\
\hline & & 2 & 65 \\
\hline & \multirow{2}{*}{ Dampak } & 1 & 57 \\
\hline & & 2 & 57 \\
\hline
\end{tabular}

Sumber: Hasil Pengolahan Data Primer (2017).

Berdasarkan Tabel 1 maka selanjutnya akan digambarkan secara kontinum yaitu sebagai berikut, contoh:

Usaha kerajinan anyaman enceng gondok dapat meningkatkan pendapatan masyarakat memiliki nilai skoring pada responden masyarakat umum yaitu 63 yang terletak pada daerah sangat setuju.

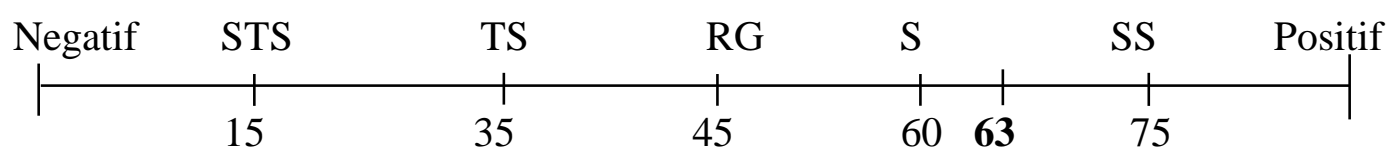

\section{Persepsi Masyarakat Pengrajin}

Dengan menggunakan teknik pengumpulan data angket/koesioner yang diberikan kepada pengrajin anyaman enceng gondok. Pengrajin eceng gondok yang ada di Desa Banyu Hirang adalah 15 orang sehingga responden yang diambil adalah 15 orang untuk masyarakat pengrajin anyaman enceng gondok dari Desa Banyu Hirang. 
Berdasarkan hasil kuesioner yang di jawab oleh masyarakat pengrajin kemudian dianalisis berdasarkan skoring setiap jawaban responden.

Tabel 2. Jumlah skor jawaban dari pernyataan untuk untuk responden masyarakat pengrajin Tahun 2017.

\begin{tabular}{|c|c|c|c|}
\hline $\begin{array}{c}\text { Sub } \\
\text { Indikator }\end{array}$ & Indikator & No Pernyataan & $\begin{array}{l}\text { Jumlah total Frekoensi } \\
\text { (orang) x skor }\end{array}$ \\
\hline \multirow{7}{*}{ Aspek Ekonomi } & \multirow{3}{*}{ Manfaat } & 1 & 63 \\
\hline & & 2 & 62 \\
\hline & & 3 & 60 \\
\hline & \multirow{4}{*}{ Dampak } & 1 & 46 \\
\hline & & 2 & 48 \\
\hline & & 3 & 62 \\
\hline & & 4 & 73 \\
\hline \multirow{5}{*}{ Aspek Sosila } & \multirow{3}{*}{ Manfaat } & 1 & 71 \\
\hline & & 2 & 61 \\
\hline & & 3 & 67 \\
\hline & \multirow{2}{*}{ Dampak } & 1 & 59 \\
\hline & & 2 & 42 \\
\hline \multirow{4}{*}{ Aspek Budaya } & \multirow{2}{*}{ Manfaat } & 1 & 54 \\
\hline & & 2 & 64 \\
\hline & \multirow[t]{2}{*}{ Dampak } & 1 & 33 \\
\hline & & 2 & 39 \\
\hline \multirow{4}{*}{ Aspek Lingkungan } & \multirow{2}{*}{ Manfaat } & 1 & 63 \\
\hline & & 2 & 68 \\
\hline & \multirow{2}{*}{ Dampak } & 1 & 47 \\
\hline & & 2 & 46 \\
\hline
\end{tabular}

Sumber: Hasil Pengolahan Data Primer (2017).

Selanjutnya akan digambarkan secara kontinum skor jawaban dari pernyataan untuk untuk responden masyarakat pengrajin, contoh :

Pengrajin sangat sulit untuk memenuhi selera konsomen sebab kreatifitas pengrajin kurang dalam hal bentuk dan pemberian aksesoris memiliki nilai skoring pada responden masyarakat pengrajin yaitu 46 yang terletak pada daerah setuju.

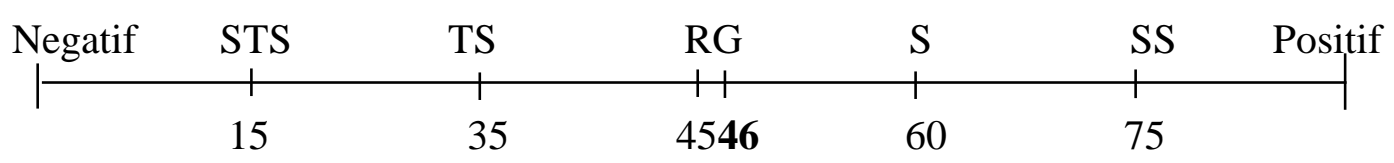

\section{Pembahasan}

Persepsi masyarakat terhadap usaha anyaman enceng gondok di Desa Banyu Hirang Kecamatan Amuntai Selatan Kabupaten Hulu Sungai Utara

Berdasarkan hasil dari pengskalaan Likert persepsi masyarakat terhadap usaha anyaman enceng gondok di Desa Banyu Hirang bahwa dari seluruh pernyaatan tentang usaha anyaman enceng gondok yang ada di desa banyu hirang terhadap dampak positif dan negatif yang dilihat dari segi aspek ekonomi ,sosial, budaya dan lingkungan.

Dapat dilihat pada tabel dibawah ini Skor rata-rata pada persepsi masyarakat umum dan pengrajin terhadap dampak negatif dan positif terhadap usaha anyaman enceng gondok. 
Tabel 3. Masyarakat umum dan masyarakat pengrajin terhadap dampak positif dan negatif usaha anyaman enceng gondok Tahun 2017.

\begin{tabular}{|c|c|c|c|c|}
\hline Indikator & Sub Indikator & No Pernyataan & Skor Umum & Skor Pengrajin \\
\hline \multirow{10}{*}{$\begin{array}{l}\text { Dampak } \\
\text { Positif / } \\
\text { Manfaat }\end{array}$} & \multirow{3}{*}{ Aspek Ekonomi } & 1 & 63 & 63 \\
\hline & & 2 & 60 & 62 \\
\hline & & 3 & 59 & 60 \\
\hline & \multirow[t]{3}{*}{ Aspek Sosial } & 1 & 63 & 71 \\
\hline & & 2 & 62 & 61 \\
\hline & & 3 & 61 & 67 \\
\hline & \multirow[t]{2}{*}{ Aspek Budaya } & 1 & 43 & 54 \\
\hline & & 2 & 61 & 64 \\
\hline & \multirow[t]{2}{*}{ Aspek Lingkungan } & 1 & 61 & 63 \\
\hline & & 2 & 65 & 68 \\
\hline & Jumlah & & 598 & 633 \\
\hline & Rata-rata & & 59,8 & 63,3 \\
\hline & Rata-rata terakhir & & & \\
\hline
\end{tabular}

\begin{tabular}{|c|c|c|c|c|}
\hline Indikator & Sub Indikator & No Pernyataan & Skor Umum & Skor Pengrajin \\
\hline \multirow{10}{*}{$\begin{array}{l}\text { Dampak } \\
\text { Negatif }\end{array}$} & \multirow[t]{4}{*}{ Aspek Ekonomi } & 1 & 50 & 46 \\
\hline & & 2 & 49 & 46 \\
\hline & & 3 & 58 & 62 \\
\hline & & 4 & 67 & 73 \\
\hline & \multirow[t]{2}{*}{ Aspek Sosial } & 1 & 54 & 59 \\
\hline & & 2 & 53 & 42 \\
\hline & \multirow[t]{2}{*}{ Aspek Budaya } & 1 & 46 & 33 \\
\hline & & 2 & 42 & 38 \\
\hline & \multirow[t]{2}{*}{ Aspek Lingkungan } & 1 & 57 & 47 \\
\hline & & 2 & 57 & 46 \\
\hline & Jumlah & & 533 & 492 \\
\hline & Rata-rata & & 53,3 & 49,2 \\
\hline & Rata-rata terakhir & & & \\
\hline
\end{tabular}

Secara kontinum persepsi masyarakat umum dan pengrajin terhadap dampak positif

pada usaha anyaman enceng gondok dapat dilihat pada gambaran di bawah ini:

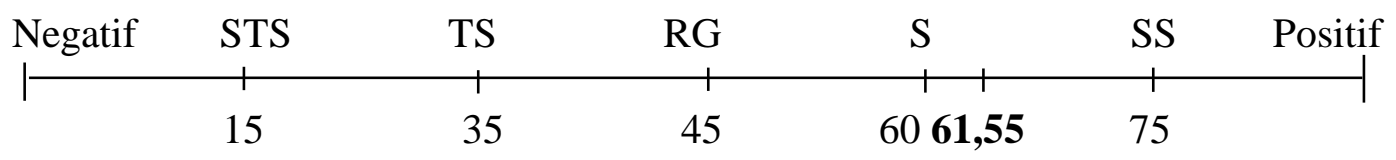

Berdasarkan penggambaran secara kontinu diatas, menggambarkan bahwa persepsi masyarakat terhadap usaha anyaman enceng gondok yang berada di Desa Banyu Hirang Kecamatan Amuntai Selatan Kabupaten Hulu Sungai Utara terhadap dampak positif dan dilihat dari segi Aspek ekonomi, aspek sosial,aspek budaya dan aspek lingkungan adalah sangat fositif/sangat setuju sebab skor rata-rata yang didapat adalah 61,55 yang berada pada daerah sangat setuju.

Secara kontinum persepsi masyarakat umum dan pengrajin terhadap dampak negatif pada usaha anyaman enceng gondok dapat dilihat pada gambaran di bawah ini:

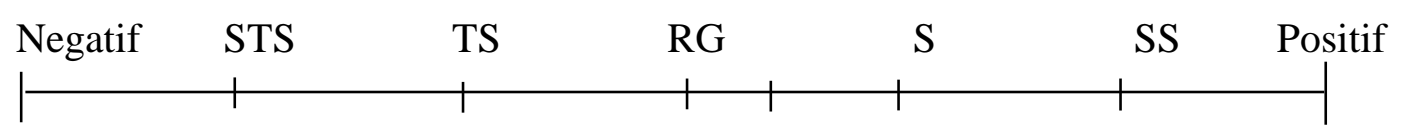


Miranda Romaully B.R. Sitanggang \& Juwairiyah, Persepsi masyarakat ..

15 35

Berdasarkan penggambaran secara kontinu diatas, menggambarkan bahwa persepsi masyarakat terhadap usaha anyaman enceng gondok yang berada di Desa Banyu Hirang Kecamatan Amuntai Selatan Kabupaten Hulu Sungai Utara terhadap dampak negatif dan dilihat dari segi Aspek ekonomi, aspek sosial,aspek budaya dan aspek lingkungan adalah setuju sebab skor rata-rata yang didapat adalah 51,25 yang berada pada daerah setuju. Sebab mereka berpendapat bahwa dampak negatif yang diberikan oleh usaha anyaman memang dirasakan oleh para masyarakat.

\section{Harapan Masyarakat}

Berdasarkan hasil dari membagi koesioner dan wawancara langsung dari masyarakat baik itu masyarakat pengrajin dan masyarakat umum dalam penelitian ini penulis mendapatkan informasi tentang harapan-harapan masyarakat terhadap usaha anyamn eceg gondok yang ada di Desa Banyu Hirang Kecamatan Amuntai Selatan Kabupaten Hulu Sungai Utara diantaranya, banyak masyarakat menginginkan adanya dukungan pemerintah dalam segi pelatihan untuk menambah kreatifitas pengrajin sehingga kalau masyarakatnya sudah bisa mengembangkan kreatifiatasnya maka pengrajin bisa menyeimbangkan selera konsomen tidak hanya itu pemasaran yang lebih luas pun di harapkan oleh masyarakat sebab pemasaranlah yang menjadi tolak ukur terhadap maju tidaknya usaha anyaman enceng gondok ini sehingga diharapkan pemerintah ikut serta dalam mempromosikan dan mencari peluang pemasran yang lebih banyak agar produk anyaman enceng gondok ini banyak di ketahui dan diminati masyarakat.

\section{KESIMPULAN}

Persepsi masyarakat terhadap dampak fositif pada usaha anyaman enceng gondok di Desa Banyu Hirang Kecamatan Amuntai Selatan dilihat dari segi aspek ekonomi, sosial, budaya dan lingkungan adalah sangat memberikan dampak positif $\begin{array}{lll}45 \mathbf{5 1 , 2 5} & 60 & 75\end{array}$

terhadap masyarakat. Sedangkan persepsi masyarakat terhadap dampak negatif pada usaha anyaman enceng gondok di Desa Banyu Hirang Kecamatan Amuntai Selatan dilihat dari segi aspek ekonomi, sosial, budaya dan lingkungan adalah memberikan dampak negatif terhadap masyarakat.

\section{DAFTAR PUSTAKA}

Dinas Perindustrian, Perdagangan, Koperasi Kabupaten Hulu Sungai Utara. 2017. Data Industri di Kabupaten Hulu Sungai Utara. Amuntai.

Sutawi. 2002. Manajemen Agribisnis. Bayu Media dan UUM Press. Malang.

Kaleka, N dan Hartono E.T. 2013. Kerajinan Enceng Gondok. Arcitra. Surakarta. 